\title{
A Case Study of Casework Tinkering
}

\author{
Maj Nygaard-Christensen ${ }^{1}$ (D), Bagga Bjerge ${ }^{2}$ (D) , Jeppe Oute ${ }^{3}$ \\ Aarhus University, Department of Psychology, Center for Alcohol and Drug Research, \\ Bartholins Allé 10, 8000 Aarhus C: Denmark \\ ( ${ }^{1}$ mnc.crf@psy.au.dk ${ }^{2}$ bb.crf@psy.au.dk ${ }^{3}$ jo.crf@psy.au.dk)
}

\begin{abstract}
Citizens with complex problems are often in touch with different welfare services and administrative systems in order to re-

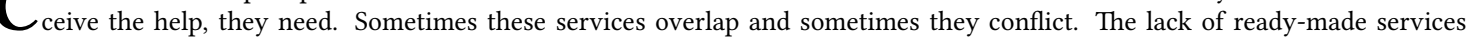
to match the complex, multiple, and often shifting needs of citizens with complex problems presents a challenge to caseworkers in the welfare system. In this article, we zoom in on the management of a single user's case, in order to examine in detail how caseworkers nevertheless make casework 'work'. We employ the concept of 'tinkering' to highlight the ad hoc and experimental way in which caseworkers work towards adjusting services to the unique case of such citizens. Tinkering has previously been used in studies of human-technology relations, among others in studies of care-work in the welfare system. In this paper, we employ the concept to capture and describe a style of working that, although not a formally recognized method, might be recognizable to many caseworkers in the welfare system. We show how tinkering involves the negotiation of three topics of concern, namely the availability of services, the potentials of services to be adjusted to the particular problems of the citizen, and finally, the potential for interpreting these problems and the citizen's needs in a way that they match the service. We further demonstrate that casework tinkering involves both short-term and long-term negotiation of services. Firstly, tinkering is involved in the continual adjustment and tailoring of services to the immediate needs of the citizen, but secondly, it also speaks to a more proactive process of working towards a more long-term goal.
\end{abstract}

KEYWORDS: citizens with complex problems, casework, case studies, tinkering.

\section{Introduction}

Caseworker 1: I can't promise that she'll be admitted [to psychiatric treatment], because that's the law. If she wants to walk free, then she can walk free.

Caseworker 2: Well, but if we don't try... and we have to try something. And so it's a bit like, what exists in the land of the possible?

\section{Caseworker 1: Right.}

Caseworker 2: And where could we do that, in order to help her?

Caseworker 1: The next best step.

In the Danish welfare system, citizens with complex problems present a particular challenge to caseworkers. This owes to the sometimes overlapping and sometimes conflicting welfare services this group of citizens often receive, and the differing professional approaches and administrative and bureaucratic systems this implicates. A recurring example is a citizen with substance use problems who is refused in the psychiatric system because of their substance use, or, as seen in the above example, might be unwilling to go into psychiatric treatment.

Danish welfare policy strategies typically operate with the idea of 'formulas' or models that respond to people's varied problems in order to 'fix' them (Vohnsen 2017, Bjerge et al. forthcoming). Tied to this view is a perception of the employees providing these services as 'problem-solvers' (cf. Spector \& Kitsuse 1977, Adams 1996, Bacchi 2009, Møller \& Harrits 2013, Payne 2014). According to this reasoning, welfare interventions should ideally contribute to transforming people with complex problems into people without problems, or at least to a significant reduction in the severity and complexity of their problems. Many social or health problems are indeed relatively easily identified and 'matched' by existing services. However, assisting individuals with complex problems and multiple needs typically involves a more complex process of crafting appropriate responses. This is due both to the often shifting life situations and severity of prob- 
lems experienced by this citizen group, as well as to the different welfare administrations that they are in touch with.

This article offers an ethnographic examination of how caseworkers working with this citizen group seek to make services work in everyday practice, despite these obstacles. We employ the concept of 'tinkering' (Bloche \& Cournos 1990, Mol et al. 2010, Winance 2010, Knorr 1979, Grommé 2015, Lydahl 2017) as a lens through which to explore the multifaceted character of casework on complex cases. So far, the concept of tinkering has mainly been employed in analyses of human-technology relations. From these studies, we take the conception of tinkering as the process by which professionals 'meticulously explore, "quibble", test, touch, adapt, adjust, pay attention to details and change them, until a suitable arrangement (material, emotional, relational) has been reached' (Winance 2010: 95). In this article, however, we extend the concept to describe the processual and experiential character by which welfare professionals piece together services to citizens that fall outside of formal welfare service models and/or between administrative welfare systems. As the article will show, this involves an ongoing process of probing and examining possible courses of action and adjusting these in order to tailor services to individuals, while at the same time measuring services against caseworkers' own interpretations of the recipient's shifting problems, needs and desires. In other words, both services and the citizen - or interpretations of the citizen's problems and needs are 'tinkered with' by caseworkers, in order to move cases forwards.

By tinkering, we do not suggest that caseworkers operate in an unskilled or shady manner, as the popular use of the term might seem to indicate. We suggest that the form of casework tinkering explored in this article in fact requires an advanced level of skill, experience, and knowledge of the welfare system and of its potentials and limits. However, there is a degree to which tinkering at times involves or even necessitates a degree of 'rule-bending' or distortion of formal regulations so that welfare assistance can be made available for a citizen whose needs might otherwise not be matched by existing services. While not a formal or rec- ognized method, tinkering might thus be required in order to make cross-sectorial casework 'work', as one such caseworker reflected when explaining: 'how the systems work together, and how you ... manoeuvre in those systems in order to make the best thing possible come through for the citizen, which the systems can't manage on their own'. Tinkering should therefore not be understood as opposed to formal methods, nor to the rules and regulations that caseworkers in the welfare system are normally guided by. Instead, we take tinkering to describe the manner by which caseworkers work towards adjusting these in a more explorative way, in order to identify appropriate responses to the often unique composite of problems and circumstances of a particular citizen.

In order to foreground these aspects of complex casework, we focus closely in on the management of a single case, that of an individual we will refer to as Marianne (cf. Nicolini 2009, Eysenck 1976: 9, Flyvbjerg 2006: 7). Our empirical point of departure is data stemming from ethnographic fieldwork at the Oasis, a temporary housing facility and drop-incentre in a medium-sized Danish municipality, where Marianne resided. On the basis of interviews, psychiatric files, and participant observation at the Oasis as well as cross-sectoral municipal meetings relating to Marianne, we will offer a detailed examination of how caseworkers 'tinker' with this particular case.

On the one hand, Marianne's case represents an example of a user who was constantly presented as 'special' and particularly complex. On the other hand, the problems that Marianne faced and the dilemmas of how to manage users with complex problems are exemplary of the cross-cutting fields of welfare services. This idea was supported by the fact that during interviews, caseworkers at the Oasis repeatedly mentioned Marianne's case as illustrative of the challenges that surround casework with people with complex problems. In the paper, we aim to identify some more generally applicable lessons on how complex cases are managed in the welfare system. We do so by zooming closely in on a particular moment in the management of Marianne's case, and exploring in detail the minute practices and negotiations of caseworkers working her case, and the descriptions and 
interpretations offered by them as they seek to move it forwards. The aim is both to 1) identify some more generally applicable lessons on how complex cases are managed in the welfare system, as well as 2) seek to capture and define a style of working that we assume that, although not a formally recognized method, will be recognizable to most caseworkers in the welfare system. In continuation of this, we will further show how conditions of uncertainty or problems open to multiple or contesting interpretations were particularly useful tools for tinkering, as they enabled caseworkers to work towards matching citizens to services that might otherwise be off limits. In the paper, we thereby argue that 1) individuals with complex problems are not easily 'fixed' since there is often no available model for how to provide services to them people; 2 ) casework practices are therefore characterised by an immense amount of reflection, negotiation and testing of hypothetical models and tools before decisions are made; and 3) the solutions suggested by caseworkers are often rejected or resisted by their recipients, so that new initiatives have to be crafted.

\section{Empirical Data}

The case study presented in this paper is part of a large, explorative, qualitative study of welfare management of people with complex problems (Christensen 2017, Oute \& Bjerge 2017, Bjerge et al. 2016). The research project focused on people simultaneously registered in drug treatment, psychiatric and employment services in Danish welfare systems in three municipalities. In the overall study, we investigated how these different problems required diverse services with different administrative tools, professional approaches and different types of national and local policies. Taken together, this combination of services, professional approaches and policies constituted a complex web of overlapping and potentially conflicting ways of managing cases.

The present study is situated in this broader research project, but is based on day-to-day field observations conducted by Jeppe Oute at the Oasis, on Marianne's social and psychiatric files, and interviews and more informal conversations with eight caseworkers. Marianne's complex problems meant that she received mul- tiple welfare services, involving caseworkers with diverse professional backgrounds and institutional affiliations. To highlight this crosssectoral character of casework, we also draw on data from an extended joint meeting. Six caseworkers from different sectors attended the meeting in order to exchange ideas, with the aim of crafting a response. Marianne's caseworkers had not invited her to take part in the joint meeting in which her case was discussed. They thus relied on their own interpretations of her problems, wishes and needs, constantly measuring these against their knowledge about available services. Marianne accepted our presence during the fieldwork, and allowed us to access her case files, but she refused to be interviewed. Understanding Marianne's perspective on the forms of casework she was subjected to would undoubtedly have provided new angles to our study. However, our primary emphasis in this article is on the professional management of her case and the multiplicity of interpretations and approaches to her problems.

At the time of our research, Marianne was in her thirties. According to her caseworkers, she had a long history of psychological, psychiatric and substance use problems. She grew up in a home with parents who struggled with drug and alcohol use as well as mental illness, and she had reportedly suffered from depression since childhood. In her adult life, she was diagnosed with schizophrenia. In her case record, she was further described as having problems with OCD, depressive symptoms, an eating disorder, and anxiety. She had been in an abusive relationship with the father of her child, a son who was now placed with a foster family. In addition, Marianne was actively using multiple substances, and at the time of our research she lived at the Oasis, a temporary housing facility for people diagnosed with psychiatric problems and drug use. Recently, her situation had worsened. Among others, she was tormented by the sensation that bugs were crawling on her skin. This often left her in a state of panic, and caseworkers recounted situations where she had hurt herself trying to remove the bugs.

One of the problems facing caseworkers working with people complex problems, is the lack of targeted services from which to assist 
people whose multiplicity of problems mean that existing service packages often do not fit their needs as understood by caseworkers. As one caseworker at the Oasis noted with reference to Marianne:

\begin{abstract}
'We have a woman who has lived here for a while, who is so ill; she's not doing well at all. And there isn't really anyone to take care of her. She doesn't belong anywhere. The only place she can be, really, is here. And we can't offer her anything. She has no insight into her own condition' (interview).
\end{abstract}

Among Marianne’s hopes for her immediate future was a wish to 'get rid of' her anxiety and to stop using drugs. In the longer term, she hoped to be able to live in her own apartment and to regain custody of her son. However, she refused to admit herself to psychiatric treatment as proposed by her caseworkers, and preferred to stay at the temporary housing facility until another solution could be found. In contrast, as will become evident below, her caseworkers saw psychiatric treatment as a preferred step towards stabilising her situation, so that more long-term planning might be possible.

\section{Casework Tinkering - An}

\section{Analytical Lens}

Studying the daily interactions in welfare institutions in order to understand the methods and dynamics of casework is hardly a new endeavour. For example, the minute details of talk-in-interaction and turn-taking in dialogues between professionals and homeless people have been studied by applying conversational analysis (Stax 2003, Rossen 2016); storytelling and staging the identities of young drug-using clients and treatment providers have been studied via narrative approaches (Andersen 2015); symbolic interactionism has been used to analyse how institutional settings frame possible meaning-making processes for interactions (Gubrium and Holstein 2001); 'peopleprocessing encounters' have analysed 'administrative allocations' (formal and informal resources and penalties) as essential for understanding how front-line work functions (Jenkins 2000, 18, Lipsky 1980); and, finally, ANT analysis has been applied to investigate how drugs, drug users, and interventions emerge in mutually constitutive sociomaterial assemblages (Nielsen \& Houborg 2015).

In contributing to this body of literature, we use the notion of tinkering to describe the ways in which caseworkers craft responses and interventions for people with complex problems in everyday practice. Tinkering refers to this continuous process of formulating welfare responses and identifying solutions through trial and error, and underlines the processual character of managing cases of individuals with complex problems. In academic work, tinkering has been used to describe scientific practices (Knorr 1979), security practices (Grommé 2015), care situations (Mol et al 2010, Winance 2010), welfare tools in healthcare clinical practice (Lydahl 2017), and design (Resnick and Rosenbaum 2013). These approaches have highlighted the role of humans and non-humans in experimenting with interventions (Grommé 2015: 232), and the process of fine-tuning technologies in relation to users/individuals or social situations (Grommé 2015, Winance 2010). Using the example of how a wheelchair is adjusted to its user, Winance (2010: 95) describes the process by which the chair is fitted as 'empirical tinkering'; a relational process involving both humans and non-humans: the chair itself, the user of the wheelchair, her husband who sometimes has to push her and the manager of the wheelchair test centre in charge of the technical adaption of the wheelchair. In this paper, we move away from this technological/material conception of tinkering, and instead use it to describe the character of the everyday crafting of casework in the Danish welfare system. We thus contribute to the broader literature on discretion in welfare work (see e.g. Lipsky 1980, Brodkin 2006, Durose 2011). However, whereas discretion is often used to characterise decisions taken on the basis of encounters between the individual street-level worker and the citizen, and to describe how on-the-spot decisions are made (for instance in the case of street-level police discretion), we use tinkering to denote the multidimensional, processual and productive character of casework when multiple welfare sectors are involved. Such casework is multidi- 
mensional because it involves multiple services which are related to different policies and bureaucratic systems (Oute \& Bjerge, forthcoming) and sometimes result in competing professional assessments of the individual. Moreover, it is processual, because quite often no particular outcome is determined; instead, managing such cases is a continuous process in which services are tailored or 'tinkered with', on an ongoing basis. Finally, it is productive, because in spite of the immense obstacles sometimes facing caseworkers, services are often made to work. This does not necessarily take place in the best possible way but, as this article seeks to demonstrate, although tinkering does not generally lead to a 'solution' or settlement of individual cases, the adjustments entailed by tinkering nevertheless serve to move cases forwards.

We suggest that in everyday casework, the employees we observed constantly negotiated three main topics or 'vectors of concern' (Vohnsen 2015), which will be explored in the remaining part of this article. These were:

1. Which services are available for crafting a case response?

2. How can these be adjusted to fit the case of this particular citizen?

3. Can the person be understood to fit the response or service?

These do not indicate a linear process, but points of attention that caseworkers continually moved back and forth between when crafting welfare responses. This was sometimes done on an individual basis, during a caseworker's everyday work, and at other times jointly, when caseworkers grouped up with colleagues in order to explore possible courses of action through which a particular citizen could be assisted.

As argued by Resnick and Rosenbaum (2013), tinkering should not be understood as opposed to planning as it is sometimes perceived. Instead, tinkerers may start out without a specific aim in mind, using a bottom-up approach, while at others times, they 'have a general goal, but they aren't quite sure how to get there' (Resnick and Rosenbaum 2013). Casework tinkering in the case examined in this paper focuses primarily on the latter: the aim is to get Marianne 'stabilised' enough that a more long-term plan can be defined, perhaps through psychiatric intervention, but caseworkers are unsure how and whether this can be achieved. More generally, we suggest that casework tinkering can be said to move along two tracks. The first was a more reactive process characterised by ongoing, minute, and sometimes day-to-day adjustments and tailoring of services and responses as Marianne's problems either worsened or improved. The second can be described as a more proactive process of working towards a more long-term goal, which may require a number of short-term adjustments or tinkering with services or interpretations of the citizen's problems and needs.

\section{Probing Possibilities}

At the joint meeting, three caseworkers from the housing facility where Marianne resided were present: Bo, the director, and Cecilie and Jette, a pedagogue and social worker respectively, who were both contact persons at the Oasis. In addition, the meeting was attended by Petra, vice director at the centre for drug treatment and socially vulnerable people in the municipality; Pernille, a nurse employed as a service coordinator in the regional psychiatric system; and Lise, a social worker who held a coordinating position in the municipality's workfare department. The meeting thus gathered together people with different professional backgrounds from different sectors of the welfare system. Not everyone present at the meeting would refer to themselves as a 'caseworker', but to avoid confusion, we will describe them as such when we refer collectively to the professionals involved with the management of Marianne's case.

The caseworkers employed at the Oasis where Marianne resided were concerned that her psychiatric problems had recently intensified and that her behaviour at the care home had become increasingly erratic. Prompted by these concerns, the aim of the joint meeting was to allow employees at different levels of the welfare system, and with varying degrees of familiarity with Marianne, to work together 
towards an intervention that might prompt an improvement in her situation and thus make future casework more manageable:

Jette: I didn't know Marianne before this. She's had problems, but these psychotic issues that you describe weren't there before. They've only appeared recently.

Bo: And that's why I say that we're seeing that she's getting worse, as you are probably all aware. What torments Marianne right now is that she's having hallucinations that she's covered with bugs, all over her body. She briefly manages to pull herself together, for maybe a minute at a time. We've repeatedly attempted to call her own doctor ... for a diagnosis, which has resulted in her admittance to the psychiatric ward, but then she's been released the following day.

While it was never directly stated as an explicit aim of the meeting, this points to the unspoken agreement that ran as an undertone of the meeting, namely that the identification of a more long-term plan for Marianne would require her to be stabilised in the psychiatric system. A key aspect of tinkering with Marianne's case was therefore to explore the possibility of admitting her to the psychiatric ward despite her own resistance to this possibility:

\section{Pernille: But I can't promise that she'll} be committed, because that's the law. If she wants to walk free, then she can walk free.

Lise: Well, but if we don't try... and we have to try something. And so it's a bit like, what exists in the land of the possible?

Pernille: Right.

Lise: And where could we do that, in order to help her?

Pernille: The next best step.

As illustrated here, throughout the meeting, legislation framing the use of coercion in the psychiatric system deprived them of that possibility under the current circumstances. As already mentioned, Marianne was unwilling to admit herself to a mental health facility, and her psychiatric records revealed how the specialist at the psychiatric department also rejected the idea of involuntary admission. Given that Marianne further lived a highly unstable life, actively used drugs and experienced psychiatric problems simultaneously, she did therefore not easily fit any existing service offers. On this background, the joint meeting attended by employees from across the relevant welfare sectors offered an opportunity for them to probe which possibilities were open - or could possibly be pried open through casework tinkering - from which to craft a response. In an interview conducted after the joint meeting, Lise commented, 'Sometimes we need to confirm that we're all going in the same direction, because if we professionals can't figure it out... I mean, it's hard enough for citizens to understand the system'. As she further emphasised, available courses of action were not always transparent or immediately known to caseworkers: 'Sometimes even I don't know who to call; sometimes I still call up reception, to ask who I should talk to. I do! They know a lot, they just do'. Due to the limited overview an individual caseworker could be expected to have of the overall range of services, tinkering served as a way to explore what the system had to offer in relation to a particular person, and to identify ways in which a case could be moved forwards. 'Tools' for tinkering could be comprised of networks, of 'knowing' the system, of being aware of the right people to talk to, of the broad range of services, rules, and exceptions to rules. Further, tinkering could involve identifying ways of accessing parts of the welfare system which were otherwise perceived as inaccessible or difficult to establish functioning relationships with (cf. Oute $\&$ Bjerge forthcoming). A recurring example of this in the case of people with complex problems was the psychiatric system, as seen in the case of Marianne, whose psychiatrist did not favour using coercion in treatment. However, the meeting offered an opportunity for them to jointly explore whether this possibility was entirely closed or could be worked around, either by exploring whether her situation was serious enough to admit her against her will, or by working with Marianne's resistance: 
Lise: We can't keep her there, if she doesn't... Even though we can plan an extended stay at the psychiatric hospital, she still has to want to be there herself.

Bo: As late as yesterday, we tried to encourage her to go to the psychiatric ward. She gets so angry, and asks if we think she's retarded.

Lise: She said directly, when I sat with her, that "there I just get a room. Here I have people". So that's her view on it. And you can't hold it against her, if that's her impression.

Cecilie: But would things be different if she was told that she would be going into outpatient drug treatment?

Bo: I think at least, Cecilie, that then you're meeting her halfway, in terms of what she wants. Her dream is to get clean.

Pernille: You could do a kind of threestep-rocket...

Lise: You and your rockets!

Pernille: But I love that expression. I think it's so good. I have such an image of it, and I think in terms of images. So if you say, if she comes to us and gets the psychotic part treated and then you say, "then you'll go and get some peace and quiet". It might just be a room, because it's damn boring at the psychiatric ward, and it has to be. Because it has to have limited stimulation and we need to shield her. And then, when the calm sets in... You can't send her out, still wildly psychotic, within 24 hours. I don't know anything about that; that's your domain, but I imagine you don't do that.

Cecilie: No, because there isn't really anywhere...

Pernille: But then you could say, "Marianne, to get you into outpatient treatment, we need to get you into shape first", or whatever you say.

As this illustrates, Marianne's rejection of psychiatric treatment did not automatically lead caseworkers to abandon this possibility. As will be clear below, the array of services avail- able to assist Marianne depended on how her situation and behaviour could be interpreted, and on the degree to which she collaborated with the direction proposed by caseworkers. For instance, their possibilities could narrow or widen depending on her current situation, such as whether she was actively using drugs. Thus, when commenting on the scenario that Marianne might stop using drugs, one of the caseworkers, Lise, suggested that this would facilitate a broadening of possibilities: 'I have to say that I'm able to offer a broader palette if she is not actively using. There's no secret in that'. However, given Marianne's particular and particularly unstable - situation, no readymade service existed from which to craft a response to her problems and needs. Hence, caseworkers had to tinker with available services, in order to see if they could be made to fit this complex case. Once the nature of Marianne's problems and her willingness to collaborate had been settled between caseworkers, they would again need to re-examine the availability of services.

\section{Tinkering with Services to Fit The Case}

The complex nature of Marianne's case meant that it was not enough for caseworkers to simply identify available services. They also had to tinker with services in order to adjust them to the particular and often unstable situation of the individual. As Lise rhetorically asked in a subsequent interview, 'How can we bend this so that we can work out how to help Marianne? What is it that we haven't yet identified in our legal system that we can do in order to back her up?'

Using the example of the role of technologies in care work, Mol, Moser \& Pols (2010) note how such technologies 'do not work or fail in and of themselves. Rather, they depend on care work. On people willing to adapt their tools to a specific situation while adapting the situation to the tools, on and on, endlessly tinkering' (Mol, Moser \& Pols 2010: 14-15). Likewise, legal openings and service packages were not fixed, but something that regularly had to be tinkered with to fit particular cases, both in the everyday work of caseworkers and in the context of crafting more targeted interventions and responses to complex cases such as Marianne's. With ref- 
erence to her study of the technical crafting and adjustment of a crime prevention intervention, Francisca Grommé describes tinkering as the 'hands-on work of adjustment in the face of surprises, disturbances, and frictions' (Grommé 2015: 233). She also says, 'tinkerers do not always aim for a balanced outcome. They may tinker according to their emerging priorities' (Grommé 2015: 233). In continuation of this, we use tinkering to denote the processual character of casework, which constantly has to be adjusted to the shifting nature of cases, as new problems emerge in the lives of individuals or their existing problems intensify or improve. However, casework tinkering in the case examined in this article can be said to move along two tracks: one relating to the ongoing, minute adjustment and tailoring of services as Marianne's problems either worsened or improved, and another process of making adjustments in the short-term, but with the aim of planning towards a more long-term goal.

Although the housing facility where Marianne stayed was intended as a short-term offer for people who would eventually move elsewhere, her caseworkers were not yet actively trying to identify another housing option for her. 'Right now it's actually the right place', Lise commented in relation to this during an interview, 'even though you should only stay as briefly as possible at a care home. "As possible" is right. There are just some things we need to take care of first, before we can be certain how to help her in the best possible way'. Even though the care home was seen as the best possible option for Marianne, they went further in their attempts to tailor the facility to her particular needs, among others by exempting her from house regulations, and by making adjustments to the resources available to her at the Oasis:

Bo: They aren't allowed to smoke in their rooms, and Marianne has been caught smoking so many times, and of course we enforced the rules, but in the end we just had to conclude that it didn't have any effect. She didn't learn any lessons from it.

Jette: To begin with, you're suspended for 24 hours, but then when we go in she just says, "Alright, I'll leave, I'll leave". Nothing about "yes, I was smoking".

Bo: She actually has a dispensation for that now. Because she smokes 24/7

Lise: You are a good person, Bo.

Bo: What should I do? Kick her out...

Marianne had also been allowed to sleep in the activity room instead of her own room, because she felt safer in closer proximity to the employees at the home, and because they worried what she might do if left on her own in her room. They reported incidents where she had tried to set fire to the bugs that she felt were crawling over her body; they worried that she did not eat enough, and were concerned about her anxiety and hallucinations. In this way, staff constantly tinkered with services to adjust them to Marianne's needs and shifting behaviour, although this sometimes caused conflicts with the other residents, who questioned what they saw as special treatment or the favouring of a particular resident. This suggests that everyday tinkering in one case may sometimes conflict with the management of others.

Tinkering could involve locating immediately available service offers. However, the complex needs of people like Marianne meant that it often also involved identifying exceptions to service restrictions or finding ways such as internal guidelines - to broaden the array of services, as suggested by Lise who commented during the joint meeting: 'Maybe we should see if we can find a rule or an exception. Because that's what we're looking for'. Marianne's resistance to psychiatric treatment did not cause them to abandon the idea of coercion. Instead, they continued to revisit and explore this possibility during the joint meeting. Among others, they circled around the question of whether her symptoms could be understood in a way that validated coercion, constantly weighing up the individual's legal rights against her 'best interest', as interpreted by the caseworkers:

Lise: I think we are restricted in terms of what we would like to do, but we are in that spectre in relation to... what are the individual's legal rights?

Int.: Yes, try to say a bit more about that... 
Lise: Well, the individual has the right to say no to what we... what every party around this table is thinking that this person, Marianne, needs...admission to the psychiatric hospital. We can't force her, and we shouldn't be able to. But we have the individual's legal rights in play, and that's a good thing, but sometimes it works against us...

Int.: A good thing for whom?

Lise: For the individual, because in 95\% of cases, it's a good thing. It's important of course that we can't go in and overrule a person's autonomy. And then we have this little group of people, where we can see that they are not in a position to know what's best for them.

In addition to probing services and examining whether and how they could be tinkered with to fit Marianne's case, tinkering with casework also involved assessing her situation and the significance of her symptoms and needs. In other words, crafting a case response also involved exploring whether the individual could be understood to 'fit' the services available to them.

\section{Tinkering with Individuals to Fit Re- sources}

At the beginning of the meeting, one of the caseworkers, Bo, provided a description of Marianne's situation, summarising her career in the welfare system and her social problems and mental health/psychological issues. Making decisions about which service offers to activate involved making decisions about the nature of Marianne's problems. How should they interpret her behaviour? One of the questions negotiated by caseworkers in the context of the meeting was whether her behaviour should be understood as a psychiatric condition which was either chronic and not likely to improve or open to improvement with the 'right' psychiatric treatment, or whether her behaviour and worsened condition primarily owed to her drug use and would thus improve if she either reduced or stopped her drug use. During the meeting, caseworkers repeatedly discussed the significance of the bugs that haunted Marianne:

Bo: In my world she's psychotic.
Pernille: She is.

Bo: So on that basis, we need her doctor. Pernille: It's not enough to be psychotic.

Bo: That's the thing. She has to be a danger to herself or to others [in order to be committed against her will].

Later in the meeting, another caseworker, Petra, questioned this attempt at classifying Marianne's problems:

Petra: If I put on my anti-psychiatry hat, I don't actually think that she is psychotic. I really don't think so. I think the depression is true, maybe there's some anxiety, because that makes sense on the basis of her history. But it's true that in the past few years, she has lived through situations that have become more and more surreal for a person to be in.

Lise: If it's not psychosis when she sees bugs, then what is it?

Petra: I'm just saying, I think these are expressions of what she's going through right now. But I also think... and you can call me naïve...

Lise: I'm just curious.

Petra: I think that in a stabilising environment, this would wear off. I don't mind losing a bet, but I really believe that. To get there is really hard, I'm aware of that. But when she responds like that to Benzodiazepines; that's not unusual for someone who's depressive and anxious.

Bo: But when she responds to the Benzodiazepines, we don't see any effect.

Petra: Okay, you don't?

Bo: We don't find that she hallucinates less or has fewer symptoms.

Petra: No no.

Lise: It just doesn't bother her as much, perhaps.

Petra: Fair enough.

The question of whether Marianne's hallucinations should be viewed as evidence of psychosis was not determined with reference to diagnostic systems alone. Instead, this probing of the significance of Marianne's symptoms linked 
up with the question of service availability; of which services could be tapped into in order to craft a response to Marianne's situation.

Using the empirical example of crime prevention at a bus stop, Grommé (2015) examines how engineers tinker with setting up a warning system aimed at reducing violence by alerting the police in the lead-up to violent events. This involved developing indicators for aggressive behaviour based on acoustic inputs. To do so, some sounds had to be foregrounded as indicators of aggression, while others - noises that might be equally loud but deemed harmless were identified as background noise, and thus tuned out. In this way, aggressive behaviour could be acted upon by foregrounding certain sounds and turning them into 'a signal for action, and therefore an object of intervention, in contrast to background noise' (Grommé, 2015: 233; also Latour \& Woolgar 1986). In line with this, casework tinkering with an appropriate response for Marianne involved the collective investigation of indicators that could support particular responses, and also included defining her in a particular way, as someone able to receive a particular intervention. In this process, some things were foregrounded while others were relegated to the background or left entirely unmentioned.

A recurring issue that was foregrounded both in interviews with employees talking about Marianne's case, as well as in the joint meeting, was her intelligence, which was brought up early the meeting, during Bo's introductory summary of Marianne's history of welfare encounters:

\section{A psychological examination in Octo- ber 2011 initiated by child and youth so- cial services summarises the test results showing that this person has a signif- icant degree of intellectual problems... she has a tested IQ of 77, equivalent to being cognitively impaired. The individ- ual therefore does not have the resources required to take care of herself in her ev- eryday life and independently solve the problems that naturally arise. She will therefore need external assistance and support in her everyday life, especially life as a single mother of a child.}

During the meeting, caseworkers would return to this issue of Marianne's intelligence, as illustrated by the following exchange between Jette and Cecilie:

Jette: In the past, I've worked with students who are mentally disabled. I feel at home when I'm dealing with her. Cecilie: You... what are you saying? Jette: I used to work with mentally disabled people. And I feel at home when I'm working with... She's taught herself a few things. She possesses some skills that perhaps not many others have. Because I think she's had to take care of herself a lot. These are coping strategies, but she can't steer away from them.

On one level, the issue of Marianne's intelligence was seen to contribute to the complexity of her case and the resulting difficulties in crafting a proper response. Petra suggested that existing offers set up to respond to individuals with drug use and mental disabilities had been crafted to target those with 'normal intelligence'. 'With someone like Marianne', she proposed, with an 'IQ at the cognitively impaired level, we need to go back and shake things up a little'. At the same time, however, the IQ test also facilitated casework tinkering. It was not directly related to the availability of appropriate services; the test did not in itself back up caseworkers in their attempt to commit Marianne involuntarily to psychiatric treatment. However, foregrounding the issue of her intelligence gave weight to the possibility of a psychiatric intervention for Marianne. It also added validity to caseworkers' repeated suggestions that Marianne was neither in a position to know, nor to decide, what was best for her: 'One moment we find that she's actually able to recognise her own situation and way of living, and then, shortly afterwards, she's completely in denial and it's impossible to correct her view of reality', the manager of the Oasis said. In other words, the issue of her intelligence and perceived inability to know what was best for her, supported their attempts to work towards securing psychiatric treatment for Marianne, in spite of her continued resistance to this. In this way, certain aspects that worked in favour of psychiatric treatment were foregrounded at the 
meeting, such as the issue of Marianne's intelligence, and the significance of bugs as indicators of psychosis. Although this in itself did not allow caseworkers to commit her against her will, it at least enabled them to continue exploring the possibility of coercing her into treatment.

In the same process, Marianne's resources were pushed to the background, or not mentioned at all, as were discrepancies between caseworkers' assessments of Marianne. In fact, in Marianne's psychiatric file, the IQ test was completely disregarded. The psychiatrist rejected the test as invalid because it had been carried out years before, in a different municipality, during a period when Marianne was actively using drugs; the file also mentioned that she had not cooperated during the test. Moreover, the psychiatrist emphasized that she had completed her basic education with average results, and on that basis argued that Marianne could therefore not be understood to be cognitively impaired. As shown above, however, the test was first put forward in the joint meeting by the leader of the Oasis, and thereafter not questioned by the other people present. Instead, as seen above, several participants weighed in on the issue, both by adding their own interpretations -working with Marianne was similar to working with the mentally disabled- and by emphasizing that with her low IQ, she required different welfare responses and service offers than those with a 'normal intelligence'.

\section{Negotiating Discrepancies - Crafting a Case Response}

Among the problems faced by caseworkers dealing with people with complex problems are the imbrication of services they receive and the conflicting approaches that sometimes arise as a result of these different bureaucratic and administrative systems. For instance, drug users with psychiatric problems have a record of being denied treatment in the psychiatric system because of their drug use. However, our examination of Marianne's case revealed how discrepancies between different bureaucratic or professional approaches and caseworkers' conflicting interpretations of an individual's problems were at other times put to the side in or- der to move a case forward. For instance, in interviews conducted after the meeting it became clear that some diverging understandings of Marianne had simply not been put forward at the meeting. Lise, from the municipality's workfare department, told us:

\begin{abstract}
And then she... supposedly... has an ... I haven't looked into this for myself, but she has an IQ that works against her, in relation to getting the help she might need in terms of treatment. I just want to say that this isn't my experience of her, from what I've seen.
\end{abstract}

At the meeting, no such disagreements or diverging understandings of Marianne were put forward. The psychiatric file in which the IQ test was rejected was not brought up, and Petra's suggestion that Marianne's level of intelligence required a differently crafted response did not meet with objections from any of the caseworkers. Moreover, when disagreements were articulated, they were quickly settled, as illustrated above with Petra's interjection that Marianne might not be psychotic. Likewise, what began with the pedagogically trained leader of the Oasis stating that in 'his world', Marianne was psychotic, and was followed by Petra questioning whether this was in fact the case, ended with caseworkers jointly rejecting Petra's contention and continuing to explore which options were available to best respond to Marianne's psychosis. In this way, discrepancies were withheld or written out of the joint task of crafting a case response. Hence, in spite of the psychiatrist's rejection of the IQ test in her psychiatric file, and other caseworkers privately doubting its results, the test played an important part in the way caseworkers moved forwards as if they were crafting an intervention for a person with a cognitive impairment. Thus, in the process of crafting a case response, conflicting professional understandings were thereby typically put to the side, sometimes intentionally, as seen in this extract from a subsequent interview with Pernille, the psychiatric nurse: 
We're all different in this cross-sectoral collaboration, and we need to be. We contribute with different things. We are positioned differently in relation to the patient. The patient is here, and then I'm over there. Take the example of Marianne: there's Bo, who has a huge amount of knowledge of Marianne. I come from out here, and so I humbly relate to what they've observed. It's my job to say that they know what this is all about. I don't question whether Marianne is psychotic or not. What they say is real enough. They have the competency to assess that. So it's fine for me to go back and refer to what they've observed, and that's what we all believe, and that's how we'll treat it.

In this way, conditions of uncertainty or situations characterised by different or contesting interpretations of the citizen's needs or problems can be said to be enabling of casework tinkering.

In an analysis of a Danish municipality's implementation of a controlled trial targeting people on sickness benefit leave, Vohnsen challenged 'conventional descriptions of streetlevel workers as a distinct group of people with distinctive concerns and attitudes to their work' (Vohnsen, 2015: 147). Instead, she suggests that street-level workers are oriented by 'vectors of concern' which guide planning and implementation processes. She identifies these as the 'concern for the citizen, the concern for the caseworker's ability to best manage the collective workload and the concern for the validity of the project' (Vohnsen, 2015: 152). Tinkering with a case response to Marianne involved a similar process of weighing up her needs against service availability and accessibility in the different welfare sectors that her case linked up with. As mentioned at the beginning of this paper, different sectors at times conflicted with each other, for example when a caseworker tried to secure psychiatric treatment for an individual who was also a drug user. However, rather than being a case of conflicting professional or sectorial interpretations of how a case should be handled, the cross-sectoral management of Marianne's case showed how decisions involved a constant process of interpreting and reinterpreting the person in relation to relevant services, which employees across all sectors were involved in. As Vohnsen emphasizes:

Concerns do not belong to people in different parts of an organization, but rather to particular problems, and are pursued in turn by all involved. Concerns, then, are not internal psychological drives but rather external and $d y$ namic perspectives which have to be juggled and weighed against each other on an hourly basis. (Vohnsen, 2015: 158)

Tinkering with a case response to Marianne involved a continuous process of exploring psychiatric classifications, the individual's legal rights, the caseworkers' assessments of Marianne's problems and needs and their personal and professional networks. As Vohnsen further shows, vectors of concern emphasise how 'what one person holds to be of importance in one specific situation is not necessarily what the same person might attribute importance to in a different situation' (Vohnsen, 2015: 158). For instance, attention to Marianne's legal rights was both foregrounded and pushed to the background during the meeting; it was foregrounded as a barrier to the caseworkers' attempts to commit Marianne involuntarily to psychiatric treatment. At the same time, it was pushed to the background in other ways, for instance by the decision not to include Marianne in the meeting. This situation bears some resemblance to the findings of a study on patient involvement in Danish psychiatry, which referred to a similar case in which the psychiatric professionals presented themselves as being in control of the patients' rights, both to determine the relevance of their health issues and to consent to the involvement of others in these issues. In the study, Oute (2018) reports how psychiatric professionals were very protective of the hierarchy between themselves and their patients, since they saw this hierarchy as the underpinnings of the system (Oute, 2018: 9, Oute \& Bjerge forthcoming). As such, concerns for a person's rights were legitimately pushed to the background or skirted around. 
No clear intervention for Marianne's case was formulated on the basis of the meeting. While caseworkers explored their ability to coerce her into psychiatric treatment, concerns for her legal rights and her unwillingness to be admitted into a metal health institution prevented them, at least for the moment, from doing so. As suggested at the outset of this paper, casework tinkering worked along two tracks: one that concerned ongoing and often day-today responses to her problems and needs as they evolved during a particularly unstable period in her life, and a second that aimed at longterm planning. Instead of committing Marianne to psychiatric treatment, her medication was altered. In a subsequent meeting, one of the caseworkers reported that this appeared to have stabilised her situation to some degree, suggesting that the meeting and collective tinkering with her case had contributed to supporting future long-term planning of her case.

\section{Concluding Remarks}

The lack of an end point in Marianne's case is exemplary of the nature of casework in the context of welfare management of people with complex problems. Unless an individual moved on to a different municipality or their situation improved radically, casework tinkering was a continuous process. By zooming in on the management of a single case and examining the multiple concerns, interpretations and ways of probing and tinkering with services to make them fit individual situations, we have underlined the processual character of casework and demonstrated how cases are made to work by tinkering around in the interstices between existing service models. Marianne's case suggests that if caseworkers and welfare institutions insist too rigorously on putting people with complex problems into narrow boxes and categories in order to provide them with services, these services are quite likely to fail. Whereas citizens like Marianne require person-centred and tailored services, each of the systems are organised around certain rationalities and forms of expertise. Paradoxically, this leaves little room for providing accurate and timely services to such citizens. Indeed, while tinkering is a required tool in everyday casework, it is rarely an acknowledged or encouraged method (see also Resnick \& Rosenbaum 2013). In this sense, a high level of skill is essential for navigating these system and thereby making casework practice effective (Winance 2010, Mol et al. 2010, Knorr 1979, Grommé 2015, Lydahl 2017).

However, these findings may not sit very comfortably with the dominating public discourse that problems need to be 'fixed' in a specific way; an approach that has been thoroughly evaluated through randomized controlled trials and which operates with the idea of measured, predictable outcomes (Vohnsen, 2017; Bjerge \& Rowe, 2017). In this sense, our paper has shown how casework practices in complex cases is often better understood by applying a concept that captures the processrelated and experimental dimensions of casework, rather than insisting that social work is or should be evidence-based, using RCTs, etc. We are not suggesting that casework should not draw on models or be evaluated and documented. Instead, we argue that the debate on welfare services would gain from insights into the intricate processes of conducting casework in practice - the professional, legal, economic and moral considerations and the continuing adjustments made - in order to understand the nature of casework in complex cases.

In addition to this, the essence of welfare services and service providers is that their role is to solve problems (cf. Spector \& Kitsuse 1977, Adams 1996, Bacchi 2009, Møller \& Harrits 2013, Payne 2014). Although the caseworkers in our study accept the idea that tinkering is a cornerstone of their daily practices, at times they too wish for other possibilities, such as going further yet towards coercing Marianne in order to fix her problems. In that sense, the daily need for tinkering in casework related to people with complex problems is experienced as key to finding suitable solutions, despite the fact that it is experienced as hard, exhausting labour that often fails to fix people's problems and makes fulfilling ones professional aspirations a convoluted process (cf. Lipsky 1980, Frank \& Bjerge 2011, Bjerge \& Bjerregaard 2017). 


\section{Acknowledgements}

Research for this article was funded by Independent Research Fund Denmark.

\section{References}

Adams, R. (1996). Social Work and Empowerment. New York: MacMillan Press.

Andersen, D. (2015). Stories of change in drug treatment: A narrative analysis of 'whats' and 'hows' in institutional storytelling. Sociology of Health and Illness, 37(5), 668-82.

Bacchi, C. (2009). Analysing Policy: What's the problem represented to be? Frenchs Forest: Australia.

Bjerge, B. \& Bjerregaard, T. (2017). The twilight zone: Paradoxes of practicing reform. Journal of Organizational Ethnography, 6(2): 100-115.

Bjerge, B. \& Rowe, M. (2017). Inside the black box of public service change. Journal of Organizational Ethnography, 6(2), 62-67.

Bloche, M. G. \& Cournos, F (1990). Mental health policy for the 1990s: Tinkering in the interstices. Fournal of Health Politics Policy Law, 15, 387-411.

Brodkin, E. (2006). Bureaucracy redux: Management reformism and the welfare state. Fournal of Public Administration Research and Theory, 17(1), 1-17.

Christensen, L. (2017). Metaphors of change. Descriptions of changes within the practice of social work for socially marginalized people. Fournal of Organizational Ethnography, 6(2), 62-67.

Durose, C. (2011). Revisiting Lipsky: Front-line work in UK local governance. Political Studies, 59, 978-955.

Eysenck, H. J. (1976). Case studies in behaviour therapy. London: Routledge.

Flyvbjerg, B. (2006). Five misunderstandings about casestudy research. Qualitative inquiry, 12(2), 219-245.

Frank, V. A. \& Bjerge, B. (2011). Empowerment in drug treatment: Dilemmas in implementing policy in welfare institutions. Social Science \& Medicine, 73(2), 201-208.

Grommé, F. (2015). Turning aggression into an object of intervention: Tinkering in a crime control pilot study. Science as Culture, 24(2), 227-247.

Gubrium, J. F. \& Holstein, J. A. (2001). Institutional selves: Troubled identities in a postmodern world. New York, NY: Oxford University Press.

Jenkins, R. (2000). Categorization: Identity, social process and epistemology. Current Sociology, 48(3), 7-25.

Knorr, K. D. (1979). Tinkering towards success: Prelude to a theory of scientific practice. Theory and Society, 8(3), 347-376.

Latour, B. \& Woolgar, S. (1986). Laboratory life: The construction of scientific facts. Princeton: Princeton University Press.

Lipsky, M. (1980). Street-level bureaucracy. Dilemmas of the individual in public service. New York, NY: Russel Sage Foundation.
Lydahl, D. (2017). Same and different. Perceptions of the introduction of person-centred care as standard healthcare. Gothenburg Studies in Sociology, Ph.D. thesis, University of Gothenburg.

Mol, A., Moser, I., \& Pols, J. (Eds.). (2010). Care in practice: On tinkering in clinics, homes and farms. Bielefeld: transcript Verlag.

Møller, M. Ø, \& Harrits, G. S. (2013). Constructing at-risk target groups. Critical Policy Studies, 7(2), 155-176.

Nicolini, D. (2009). Zooming in and out: Studying practices by switching theoretical lenses and trailing connections. Organizational Studies, 30(12), 1391-1418.

Nielsen, B. \& Houborg, E. (2015). Addiction, drugs and experimentation: Methadone maintenance treatment between 'in here' \& 'out there'. Contemporary Drug Problems, 42(4); 274-288.

Oute, J. (2018). 'It's a bit like being a parent': A discourse analysis of how nursing identify can contextualize patient involvement in Danish psychiatry. Nordic Journal of Nursing Research, 38(1), 1-10.

Oute, J. \& B. Bjerge. (2017) What role does employment play in dual recovery? A qualitative meta-synthesis of cross-cutting studies treating substance use treatment, psychiatry and unemployment services. Advances in Dual Diagnosis, 10, 3: 105-119.

Oute, J. \& B. Bjerge. (Forthcoming). Ethnographic reflections on accessibility to care services. Journal of Organizational Ethnography.

Payne, M. (2014) [1990]. Modern social work theory. Basingstoke: Palgrave Macmillan.

Resnick, M. \& Rosenbaum, E. (2013). Designing for tinkerability. Pp. 163-181 in: Honey, M. \& Kanter, D. E. (Eds.), Design, make, play: Growing the next generation of STEM innovators. New York, NY: Routledge.

Rossen, C. B. (2016). Pakkeudredning i det danske sundhedsvæsen: en analyse af udredningsprocesser $i$ pakkeforløb. PhD thesis. Odense: Institut for Regional Sundhedsforskning, Syddansk Universitet.

Spector, M. \& J. I. Kitsuse (1977). Constructing Social Problems. San Francisco, CA: Benjamin-Cummings Publishing Company.

Stax, T.B. (2003). Fordi ingen er ens - eller...? En analyse af tre hjemløse klienters strategier på et lokalcenter. Pp. 164-191 in: Järvinen, M. \& N. Mik-Meyer, N. (Eds.) At skabe en klient. København: Hans Reitzels Forlag.

Vohnsen, Nina Holm (2015) Street-level Planning: The shifty nature of "local knowledge and practice". fournal of Organizational Ethnography, 4(2): 147-161.

Vohnsen, N. H. (2017). The Absurdity of Bureaucracy. How implementation works. Manchester, UK: Manchester University Press.

Winance, M. (2010). Care and disability. Practices of experimenting, tinkering with, and arranging people and technical aids. Pp. 93-117 in: Mol, A, Moser, J and Pols, J (Eds.). Care in Practice. On tinkering in clinics, homes and farms. Bielefeld: transcript Verlag. 


\section{About the Authors}

Maj Nygaard-Christensen, PhD, is Assistant Professor at Centre for Alcohol and Drug Research, Aarhus University. She holds an MA and a PhD in anthropology. Her research interests are ethnographically oriented studies of political and development interventions and policy implementation processes. Her current research projects focus on marginalized Greenlanders in Denmark, poverty, and violence among socially marginalized citizens.

Bagga Bjerge, $\mathrm{PhD}$, is Associate Professor at Centre for Alcohol and Drug Research, Aarhus University. She is trained within anthropology and sociology. Her re- search activities are mainly based on qualitative methods focusing on policies and policy implementation, bureaucracy, social work as well as social marginalization. Currently, her research projects focus on poverty, drug scenes in Copenhagen, marginalized Greenlanders in Denmark and the management of citizens with complex cases.

Jeppe Oute, $\mathrm{PhD}$, is Assistant Professor at Centre for $\mathrm{Al}$ cohol and Drug Research, Aarhus University. He holds an MA in Educational Anthropology and a PhD in Social studies in Medicine. Oute's research interests are twofold. His research focuses on the social effects of mental health policy in psychiatric and drug treatment practices and on the societal and professionalinstitutional contingency of recovery and stigma in the mental health field. 